\title{
RESÍDUOS E ABFÄLLE: UM RECONHECIMENTO TERMINOLÓGICO PARA A BUSCA DE EQUIVALÊNCIAS ENTRE O PORTUGUÊS E O ALEMÃO*
}

\author{
Leonardo Zilio** \\ Mônica Linck Feijó Fichtner*** \\ Maria José Bocorny Finatto****
}

\begin{abstract}
RESUMO: No âmbito da busca de equivalentes em alemão para termos em português em um glossário de gestão ambiental desenvolvido no grupo Termisul, este trabalho descreve o caminho percorrido até a identificação da unidade que recebe o estatuto de equivalente e descreve a ocorrência dos Komposita em textos relacionados ao campo conceitual residuos e Abfälle. O trabalho foi efetuado com corpora distintos para a análise da terminologia sobre resíduos nas duas linguas. Como resultados, vemos que o pareamento português brasileiro/alemão não é absoluto, principalmente pela não existência em alemão de subcategorias de Abfälle semelhantes às que há em português brasileiro para resíduos. Isso não impede a indicação de um equivalente para o consulente, embora haja casos de lacunas conceituais e/ou denominativas. A correlação de fontes mostrou-se um elemento importante para a validação segura da informação oferecida ao consulente. No que tange aos Komposita observados, houve a maior ocorrência de termos compostos por dois elementos. Além disso, vimos que o termo Abfälle aparece exclusivamente como base, enquanto Abfall e Müll aparecem mais como determinan-
\end{abstract}

* Este trabalho é fruto de pesquisa realizada com o apoio do CNPq e da Pró-Reitoria de Pesquisa da Universidade Federal do Rio Grande do Sul.

** Bacharelando em Letras - UFRGS. Bolsista de IC-CNPq do Projeto Termisul. leonardozilio@yahoo.de

*** Tradutora, bacharela em Letras - UFRGS. Auxiliar de pesquisa voluntária do Projeto Termisul. monicalff@terra.com.br

**** Pesquisadora do Projeto Termisul e do Projeto TextQuim, docente do PPG-Letras - UFRGS, Departamento de Letras Clássicas e Vernáculas. mfinatto@terra.com.br 
tes. Ao que tudo indica, o cenário comunicativo influencia a escolha e a feição dos termos.

UNITERMOS: tradução; terminologia de resíduos; terminologias em alemão; validação de equivalentes; glossários especializados.

ABSTRACT: Based on the search for German equivalents in Portuguese for a glossary on environmental management which has been developed by Termisul research team, this paper describes both the research which was carried out to identify the unity which receives the status of equivalent and the occurrence of Komposita in texts related to residuos ("wastes") and Abfälle. The research was carried out with distinct corpora for the analysis on wastes terminology in Portuguese and German. As a result, we observed that there is no absolute equivalence between Brazilian Portuguese and German, especially because there are subcategories of Abfälle in German which does not correspond to the subcategories of residuos in Portuguese. Such a fact does not make it impossible to indicate an equivalent for the reader, although there are cases of conceptual or denominative gaps. The contrast among the equivalent sources was important to validate the information offered to the reader. From the point of view of the observed Komposita, there was a larger occurrence of terms formed by two elements. Moreover, we noticed that the term Abfälle just occurs as a base term, while Abfall and Müll occur as determiners most of the times. The research indicates that the communicative scenario has an important influence on the selection and on the characteristics of the terms.

KEYWORDS: translation; wastes terminology; German terminology; equivalents validation; specialized glossaries.

\section{Introdução}

O grupo Termisul (www.ufrgs.br/termisul) está concluindo um glossário básico de termos de Gestão Ambiental, obra que toma como ponto de partida a terminologia empregada no português brasileiro. Além de definições em português, traz in-

TRADTERM, 12, 2006, p. 269-292 
formações sobre o uso da terminologia em diferentes tipos de textos e a indicação de denominações equivalentes em línguas estrangeiras para os termos em português. Esses equivalentes são apresentados em quatro idiomas: alemão, inglês, francês e espanhol.

Os equivalentes em língua estrangeira correspondem às denominações utilizadas em gêneros textuais semelhantes ao gênero textual em que foi encontrado o termo em português. Assim, por exemplo, para localizar um equivalente em alemão para um termo como impacto ambiental, utilizado em uma norma ISO 14000 brasileira, foi localizada a norma correspondente válida na Alemanha. No texto dessa norma, é identificada uma denominação paralela que seja conceitualmente semelhante à forma em português.

A Gestão Ambiental é uma área de conhecimento multidisciplinar e ainda em fase de consolidação no Brasil, estando mais desenvolvida em vários outros países que a adotaram antes de nós. Em função disso, ao que parece, a linguagem que veicula esse conhecimento, no nosso país, tende à variação terminológica, a sofrer influência de outras línguas e, ainda, a exibir lacunas de denominação vernácula para alguns conceitos já bem consolidados e disseminados em outros países e culturas.

Nessas condições, empreender um reconhecimento do vocabulário brasileiro de Gestão Ambiental torna-se algumas vezes uma tarefa problemática. É uma tarefa que exige, tanto do terminólogo que lida com a língua portuguesa quanto do profissional de tradução que busca suas correspondências estrangeiras, um trabalho específico de pesquisa para cada campo conceitual ou recorte temático, de forma que se possa fornecer uma informação sobre a linguagem e as terminologias de uma maneira segura e confiável.

No grupo Termisul, tanto nesse glossário como em trabalhos dicionaristicos anteriores (Krieger et al., 1998 e Krieger et al., 2004), quando buscamos equivalentes em lingua estrangeira para um termo utilizado no Brasil, sempre temos feito um pareamento denominativo e conceitual com base em fontes textuais de ocorrência. Por exemplo, para identificar o equivalente 
em alemão do termo tratamento de efluentes, de acordo com nossa metodologia de trabalho, será preciso pesquisar, a partir de uma bibliografia especializada semelhante entre as duas línguas, toda uma categorização de noções e de nomes correspondentes para cada língua e realidade envolvidas. Desse modo, acreditamos, encontra-se uma denominação realmente compatível com o uso e com o significado do termo em português.

Em meio a essa sistemática de trabalho, este artigo relata um estudo desenvolvido em decorrência da nossa necessidade de compreender o funcionamento e as correlações das denominações ligadas ao tema dos resíduos no par de línguas português-alemão com vistas à identificação de equivalentes para a terminologia brasileira que figura no glossário. A busca de semelhança conceitual, conforme pretendemos demonstrar mais adiante, nem sempre é um processo facilitado, sobretudo pela maneira de organização das informações em documentos brasileiros.

Este nosso trabalho, que é um relato da busca pelo reconhecimento denominativo e conceitual no campo dos resíduos em português e em alemão, está organizado em três partes. A primeira parte apresenta nossos objetivos, materiais textuais e métodos de pesquisa e de condução do reconhecimento. Esses materiais textuais, nossos corpora, foram divididos em "mais especializados" e "menos especializados".

A segunda parte, intitulada "Resultados", compreende duas seções: a) do reconhecimento da organização conceitual e das nomenclaturas em alemão e em português, de forma a se obter um paralelo de noções e designações; b) uma seção dedicada à observação, por amostragem, da terminologia alemã formada por justaposição de duas ou mais palavras em uma única unidade lexical, unidade denominada Kompositum (plural = Komposita).

A terceira parte deste artigo traz uma sintese dos resultados, tanto do reconhecimento conceitual quanto da identificação dos Komposita. Ao final dessa parte, tecemos algumas considerações sobre a importância do trabalho de reconhecimento de equivalência terminológica. 


\section{Objetivos, materiais e métodos}

Ao buscar um reconhecimento terminológico parcial na temática dos resíduos, conforme já mencionamos, tomamos como ponto de partida os usos da terminologia de Gestão Ambiental em português. Com parcial, queremos dizer aqui que não há o objetivo de um reconhecimento completo do modus dicendidessa área de conhecimento, o que implicaria reconhecer vários outros elementos, tais como fraseologias e tipologias textuais.

Nesse reconhecimento parcial, aqui ilustrado, buscamos identificar noções e designações nas línguas portuguesa e alemã apenas para estabelecer equivalências terminológicas em um sentido bastante estrito ou operacional. Entendemos aqui, grosso modo, por equivalência terminológica "a correspondência conceitual aproximada entre um termo em lingua-fonte e um em lingua-alvo num contexto especializado" (Zilio \& Finatto, 2005).

A equivalência terminológica ocorre quando duas unidades terminológicas de línguas distintas, analisadas em textos originários de uma mesma área do conhecimento, apresentam uma definição aproximada. A aproximação definicional consiste em um mesmo gênero próximo e diferenças específicas semelhantes entre as duas línguas em foco (para mais detalhes sobre elementos da definição terminológica, veja Krieger \& Finatto, 2004).

Desde já salientamos que a busca por uma equivalência terminológica não implica tradução ou equivalência tradutológica. Quer dizer, não se trata de traduzir para a língua alemã um termo em português, ${ }^{1}$ mas sim de identificar como, em alemão, num mesmo ambiente textual, uma mesma noção pode ser expressa. Nessa identificação, procuramos localizar, inclusive, eventuais variações denominativas presentes em um mesmo texto ou as variações que ocorrem em função de diferentes situações textual-

\footnotetext{
1 Não entramos aqui no mérito da discussão sobre a diferença entre equivalência e correspondência em tradução. Acreditamos que qualquer tradução implica uma re-textualização da língua-fonte para a língua-alvo. Isso, naturalmente, implica em um todo de texto. Palavras, expressões ou "termos técnicos" em isolado, desconectados de seu ambiente textual de ocorrência, não fazem sentido. Em um glossário de termos como o nosso, o grande desafio, quando se apresentam termos equivalentes em linguas estrangeiras, é vincular a designação a um determinado ambiente textual.
} 
comunicativas, levando em conta, inclusive, freqüências maiores ou menores de uso de uma determinada forma do termo.

A escolha pela subárea dos resíduos decorre de sua importância na Gestão Ambiental empresarial brasileira. Ao supor o tradutor como um dos usuários do nosso glossário, torna-se importante fornecer informações sobre os usos dessa terminologia, desde aquelas sobre um termo "mais especializado", empregado numa lei ou norma técnica, até outras sobre um termo que ocorra mais informalmente em textos de divulgação jornalística.

Caracterizaremos, a seguir, os materiais textuais utilizados para o reconhecimento que foi empreendido. Os nossos corpora perfazem dois grupos de textos tomados em paralelo, nas duas línguas. O primeiro foi utilizado para o reconhecimento nocional. O segundo, para uma observação de incidência de um determinado grupo de Komposita. Ambos estão divididos em dois segmentos: "mais especializado" e "menos especializado".

Tratar dos Komposita em meio a um reconhecimento de terminologias é importante porque esse tipo de processo de formação de palavras, típico da língua alemã, em geral corresponde a um sintagma nominal em português. E, como a apresentação sob a forma de sintagmas ou grupos nominais é maioria no universo das terminologias em português, a relação entre terminologia em português e Komposita em alemão tende a ser muito presente.

Um Kompositum corresponde a uma palavra da língua alemã que é gerada pela união de dois ou mais constituintes lexemáticos em uma estrutura composta por determinante(s) e base (Cort, 1982; Weinrich, 1993; Duden, 1998; Wahrig, 2000). Um exemplo é Hausmüll (lixo de casa/doméstico), em que o elemento Haus é o determinante e Müll é a parte que corresponde à base. Neste trabalho, em função da grande variedade de tipos de formação de Kompositum, assunto que não abordaremos, enfocamos apenas Komposita formados por dois ou mais substantivos. 


\subsection{Materiais textuais para o reconhecimento conceitual e denominativo}

Para o reconhecimento da terminologia de resíduos, utilizamos quatro corpora. ${ }^{2}$ Esses corpora foram segmentados em dois grupos de textos: um grupo de caráter mais especializado e outro do tipo menos especializado.

A divisão dos textos entre mais especializados e menos especializados se deu por uma suposição de que cada um dos âmbitos poderia compreender, conforme indica Hoffmann (2004) diferentes sublinguagens em função do tipo de público a qual os dois grupos de textos se destinam. Entende-se por sublinguagem "um recorte de elementos lingüísticos e de suas relações estabelecidas de uma temática delimitada" (Hoffmann, 2004). Existindo uma diferença entre as sublinguagens utilizadas, haverá uma possibilidade grande de ocorrer uma diferença também sobre conceitos e termos.

A divisão entre fontes mais e menos especializadas, esclarecemos, não implica qualquer apreciação quanto à validade ou importância das terminologias envolvidas ou dos próprios textos. É somente uma referência inicial, um recurso teórico-metodológico para auxiliar nossa compreensão sobre a distribuição de conceitos e da terminologia ao longo de um acervo textual de composição heterogênea.

Os corpora mais especializados, com textos escritos originalmente em português brasileiro e alemão, compreendem textos de caráter paralegal e normativo. Os menos especializados, também escritos originalmente em português e alemão, são formados por textos coletados em websites institucionais que trouxessem informações sobre resíduos e meio ambiente. Para caracterizar os websites selecionados para a coleta de textos, vale dizer que foram escolhidos aqueles que se preocupassem em trazer ao leitor/usuário o maior número possivel de informações sobre tipos e tratamentos de resíduos, sendo privilegiados os

2 Corpora, singular corpus, corresponde a um conjunto de textos em formato digital, organizado para um fim específico e passivel de ser explorado com apoio informatizado. Para maiores detalhes, veja Berber Sardinha (2004). 
que oferecessem definições para cada tipo de resíduo apresentado ou citado.

No que se refere aos corpora em português, os textos colocados no âmbito mais especializado foram: a) as normas NBR ISO da série 14000; b) o texto de um projeto de lei para a classificação brasileira dos resíduos sólidos, o Relatório Preliminar da Política Nacional de Resíduos Sólidos, abreviado doravante por RPPNRS; e c) os textos de duas resoluções sobre resíduos do Conselho Nacional do Meio Ambiente - CONAMA.

O segmento mais especializado em alemão compreende normas DIN ${ }^{3}$ - ISO da série 14000 e textos de leis alemãs sobre o meio ambiente.

Ao corpus menos especializado do português pertencem textos de vários websites, dentre eles, da organização Ambiente Brasil (www.ambientebrasil.com.br) e do Instituto para a Democratização de Informações sobre Saneamento Básico e Meio Ambiente (www.resol.com.br). O material textual menos especializado em alemão também é composto por textos de websites, como, por exemplo, o do Bayerisches Staatsministerium für Umwelt, Gesundheit und Verbraucherschutz (Ministério Estadual da Baviera para o Meio Ambiente, Saúde e Proteção ao Consumidor, www.stmugv.bayern.de) e do Umweltdatenbank (Banco de Dados sobre o Meio Ambiente, www.umweltdatenbank.de).

\subsection{Materiais textuais para a averiguação de presença de Komposita}

Para verificar a incidência de Komposita em alemão, utilizamos dois corpora comparáveis, também divididos entre textos mais e menos especializados. O material mais especializado compreende três leis brasileiras e três leis alemãs sobre resíduos. $\mathrm{O}$ conjunto de textos do tipo menos especializado, que é um corpus paralelo, ${ }^{4}$ é integrado por um guia ambiental bilíngüe alemão-

\footnotetext{
3 DIN - Deutsches Institut für Normung (Instituto Alemão para Normatização), instituição semelhante à brasileira ABNT.

4 Um corpus comparável é formado por um par de textos em duas línguas diferentes, que tratam de tema semelhante ou idêntico, sendo que um
} 
português $\left(1^{\circ}\right.$ Guia de Tecnologias Ambientais Brasil-Alemanha, 1999-2000).

\subsection{Identificação de estruturas conceituais}

Para identificação da organização conceitual presente nos textos, recorremos à elaboração de árvores de domínio. Uma árvore de domínio é um esquema hierárquico que visa representar uma organização de conceitos, procedimento usual da pesquisa em Terminologia. É um recurso de representação bastante útil para "que se tenha uma aproximação inicial a uma área de conhecimento", pois "mostra inter-relações conceituais de uma especialidade" (Krieger \& Finatto, 2004).

Entretanto, vale salientar que esses esquemas hierárquicos de noções devem ser configurados partindo-se das informações e definições encontradas nos textos de uma especialidade que se queira reconhecer. Assim, com a leitura dos materiais selecionados nas duas linguas, buscamos identificar uma hierarquia para os diferentes resíduos mencionados e definidos.

Após cuidadoso exame das informações, foram elaboradas diferentes árvores de domínio, uma para cada um dos textos e uma para o conjunto geral dos corpora.

\section{Resultados}

\subsection{Organização conceitual em árvores de dominio}

\subsubsection{Textos brasileiros do tipo mais especializado}

Pudemos observar, nos textos mais especializados brasileiros de caráter paralegal, uma certa falta de homogeneidade de noções entre um e outro. E, ao longo de um mesmo texto, verificamos algumas aparentes falhas de inter-relacionamento de definições. Essas falhas, como veremos a seguir, geram proble-

não é tradução do outro. Um corpus paralelo é composto por dois textos em duas linguas diferentes, sendo um a tradução do outro. 
mas para uma identificação de hierarquia de nomes e de noções, causando dificuldade especialmente para a geração das árvores de domínio que abranjam mais de um documento.

Algumas inconsistências internas, por exemplo, verificamos no Relatório Preliminar da Política Nacional de Resíduos Sólidos (RPPNRS). Nesse texto, algumas categorizações e definições chegam a produzir incoerências ou sobreposições de sentido. Vejamos um exemplo: há uma divisão para resíduos sólidos em resíduos comuns e resíduos especiais. Todavia, não há uma definição nesse texto que evidencie, de modo claro, por que motivo esses resíduos deveriam ser assim categorizados. Mais adiante, no mesmo documento, vemos como uma subcategoria de resíduos especiais os resíduos de serviços de saúde. Instaurando uma verdadeira circularidade ou sobreposição nocional, resíduos de servicos de saúde são definidos como

"[resíduos especiais] provenientes de qualquer unidade que execute atividades de natureza médico-assistencial às populações humana ou animal, centros de pesquisa, desenvolvimento ou experimentação na área de farmacologia e saúde, bem como os medicamentos vencidos ou deteriorados."

Como uma subcategoria de resíduos de serviços de saúde vemos, além de resíduos sépticos, resíduos perigosos e resíduos radioativos, resíduos comuns, sem nenhuma definição que diferencie esse termo (resíduos comuns) daquele mencionado anteriormente.

O fato do hiperônimo (resíduos comuns) ser encontrado também como hipônimo (subordinado a resíduos de serviços de saúde) gera, como é fácil deduzir, uma dificuldade de compreensão sobre o modo de organização dos conceitos e de suas denominações. Isso se agrava justamente pelo fato de não haver, no texto, informações definicionais que diferenciem os dois termos ou que apontem para uma relação de sinonímia.

Nossa dificuldade de compreensão da estrutura nocional, fruto de uma não explicitação do texto, pode ser verificada no esquema a seguir. Esse esquema é uma parte da árvore de domínio que elaboramos a partir do texto do RPPNRS.

TRADTERm, 12, 2006, p. 269-292 


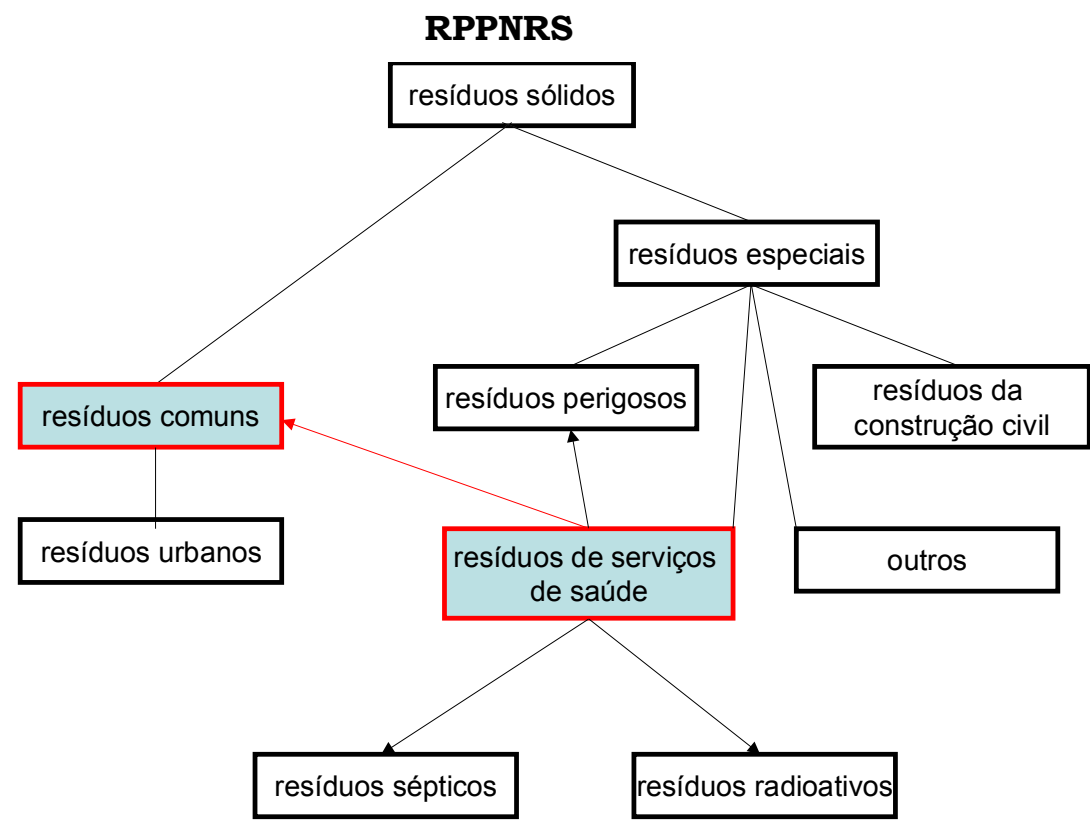

Prosseguindo o reconhecimento, vimos que outros textos paralegais também ofereciam uma organização de noções problemática. No texto da Resolução do Conselho Nacional do Meio Ambiente (doravante Res. CONAMA) n 005/93, documento específico sobre resíduos sólidos de serviços de saúde, observamos que as subcategorizações são diferentes das do RPPNRS. Segundo essa Res. CONAMA, os resíduos sólidos de serviços de saúde dividem-se em resíduos biológicos, resíduos químicos, resíduos radioativos e resíduos comuns. O esquema a seguir ilustra o relacionamento entre os termos, depreendido a partir dos conceitos explicitados no documento.

Res. CONAMA 005/93

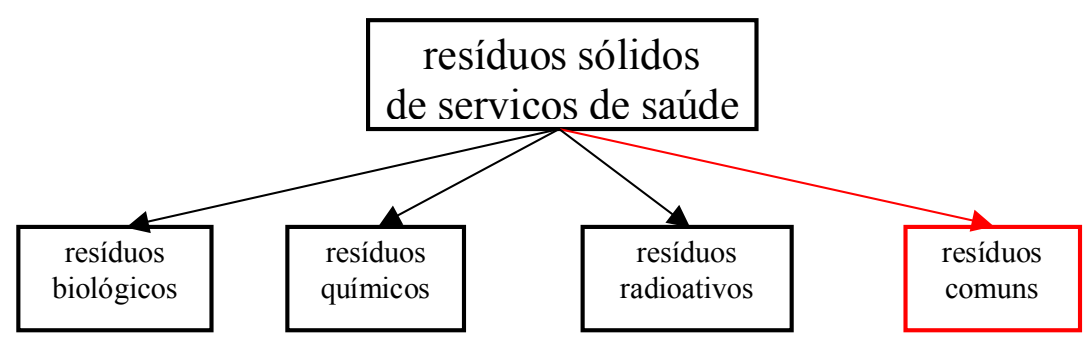

TradTerm, 12, 2006, p. 269-292 
Um problema aqui é que, na seqüência do esquema, os resíduos comuns citados na Res. CONAMA 005/93 incluem resíduos de cozinha, resíduos finais, resto alimentar, material reciclável e entulhos de obras. Ao reexaminar o RPPNRS, percebemos que entulhos de obras é uma variante para resíduos da construção civil, e que essa denominação se encontra no mesmo nível de resíduos de serviços de saúde, ou seja, como hiperônimo, e não como hipônimo. Observamos, assim, que entre nossos textos paralegais há interessantes divergências de categorização para resíduos.

Grande parte dessa estruturação heterogênea das categorias de resíduos ocorre porque a definição de cada termo é feita, no Brasil, sempre pela origem do resíduo. Quer dizer, em vez de indicar materiais ou substâncias de que os resíduos são constituídos, a definição do documento menciona, de um modo singelo, como no exemplo acima, apenas que provêm dos serviços de saúde. Explicitam-se somente seus pontos de origem.

No item seguinte, 3.1.2, veremos que a classificação alemã para os resíduos, de um modo geral, é bastante diferente, bem mais detalhada. Essa diferença de enfoque naturalmente dificultará a identificação de uma equivalência de denominações português-alemão. De outro lado, conforme entendemos, o detalhamento germânico tende a facilitar a compreensão da sistemática de categorização envolvida.

Em sintese, podemos dizer que há, nos textos brasileiros de resoluções e de projetos de lei, certo descompasso conceitual.

Do mesmo modo, nas Normas ISO 14000 brasileiras, percebemos também algumas sobreposições para a classificação de resíduos. Um exemplo disso é a norma ISO 14004. Na sua formulação original em inglês, ${ }^{5}$ há o termo wastes; na norma em alemão temos Abfällen (declinado no dativo); e, em português, versão brasileira para a norma em inglês, há uma dupla indicação de termos: resíduos (rejeitos). O usuário dessas diretrizes,

5 Pelo fato de as normas ISO serem originalmente escritas em inglês e posteriormente traduzidas para a lingua de cada país que as adote, achouse interessante que se falasse também da norma em inglês. A tradução fica a cargo da instituição nacional de normas técnicas de cada país. Essa instituição, no Brasil, é a ABNT.

TRadTerm, 12, 2006, p. 269-292 
no Brasil, em função das duas possibilidades de denominação, não terá como saber qual deles seria o termo mais adequado.

\subsubsection{Textos alemães do tipo mais especializados}

Ao examinarmos leis alemãs, vemos que todas estão fundamentadas num mesmo texto-fonte, evitando-se a variação denominativa. Isso provavelmente indica uma maior preocupação em não causar dificuldades conceituais ou denominativas, como as que ocorrem, por exemplo, na normatização brasileira sobre o tema. As duas grandes categorias de resíduos, em alemão não são, como no Brasil, resíduos especiais e resíduos comuns, mas sim Abfälle zur Beseitigung (resíduos para destinação final) ${ }^{6}$ e Abfälle zur Verwertung (resíduos para reciclagem). Essas podem ser consideradas supercategorias, pois estão marcadas em cada tipo de resíduo descrito dentro de cada subcategoria mencionada. Essa configuração foi verificada no decreto Verordnung zur Umsetzung des Europäischen Abfallverzeichnisses (Decreto para transposição da classificação européia de resíduos).

Para entender melhor a organização do campo conceitual Abfälle, é preciso explicar que esse campo conceitual em alemão está dividido em um número fixo de subcategorias de resíduos e que cada uma delas é definida pela sua composição. Quer dizer, em vez de lidar com "resíduos provenientes de", as leis alemãs mencionam que materiais ou substâncias fazem parte de cada tipo. Por exemplo, para Abfälle aus der Humanmedizin oder tierärztlichen Versorgung und Forschung (resíduos de medicina humana e de medicina veterinária, inclusive de pesquisa veterinária), encontramos Körperteile und Organe (partes do corpo e órgãos). Cada uma das leis alemãs que consultamos usa essa mesma categorização e informa o que é cada um dos tipos: se Körperteile und Organe (partes do corpo e órgãos) forem Bioabfälle (resíduos orgânicos), estará indicado que eles são Bioabfälle na lei alemã específica sobre os resíduos orgânicos.

\footnotetext{
6 As denominações entre parênteses após os termos em alemão são traduções para que o leitor não familiarizado com a língua estrangeira tenha uma noção aproximada do que representam tais termos. Elas não são equivalentes.
} 
O mesmo ocorre para os Abfälle zur Verwertung (resíduos para reciclagem), para os überwachungsbedürftige Abfälle (resíduos que necessitam de controle) e para os besonders überwachungsbedürftige Abfälle (resíduos que necessitam de controle especial).

\subsubsection{Textos de websites do Brasil e da Alemanha}

No âmbito dos textos de divulgação, ou seja, nos textos menos especializados, encontramos muito mais variação denominativa. Não só no português brasileiro, mas também nos textos em alemão.

Podemos começar nosso reconhecimento, nesta parte dos textos, pelo fato de que o termo resíduos já não seja relativamente tão freqüente em websites brasileiros, sendo substituído, em muitos casos, por lixo. Do mesmo modo, não se usa somente a expressão resíduos urbanos, mas também lixo urbano.

Em alemão, observamos um comportamento terminológico semelhante: em vez de praticamente só ocorrer Abfälle, como vimos nas leis, encontramos, nos websites, Müll ${ }^{7}$ como uma forma de indicar o mesmo conceito denominado por Abfall.

Os textos de websites também se mostraram mais complexos quanto à categorização dos conceitos, dificultando o desenho de nossas árvores de domínio. A impressão que tivemos foi que cada website, tanto no Brasil quanto na Alemanha, apresenta os conceitos da forma como melhor parece ao autor/redator do texto, sem uma preocupação didática.

Os motivos para a classificação bem mais heterogênea da que se vê em textos mais especializados parecem ser diferentes em cada país ou língua. Os textos mais especializados brasileiros não exibem uma categorização em comum e, quando mencionam alguma hierarquia, não explicam o que compreende cada uma das categorias utilizadas e nem por que estão dispostas de uma determinada forma.

\footnotetext{
7 Encontram-se nas leis alemãs, como denominações para tipos de resíduos, apenas três termos com Müll: Sperrmüll (resíduo volumoso), $\underline{\text { Hausmüll }}$ (resíduo de casa/doméstico), Siedlungsmüll (resíduo de povoamento/urbano).
} 
A imprecisão conceitual de normatizações, no Brasil, ao que parece, praticamente obriga os redatores de textos de websites a estabelecer sua própria classificação de resíduos. Essa impressão dá-se pela menção, nos websites, das normas e leis brasileiras.

$\mathrm{Na}$ Alemanha, ao contrário, os textos de normas são bastantes objetivos, uniformes, no que tange à classificação. Ainda assim, vimos, nos textos em alemão, uma diferença terminológica bem acentuada entre textos mais e menos especializados: enquanto no texto legal está presente a longa expressão Abfälle aus der Humanmedizin oder tierärztlichen Versorgung und Forschung (resíduos de medicina humana e de medicina veterinária, inclusive de pesquisa veterinária), no texto de divulgação germânico temos, simplesmente, Krankenhausabfälle (resíduos hospitalares) ou Klinikmüll (lixo de clinica). Esses termos são cunhados a partir de elementos lexicais que correspondem a palavras do cotidiano, como Krankenhaus (hospital) e Klinik (clínica). Há, assim, uma simplificação denominativa em termos da simplificação e extensão dos Komposita.

\subsubsection{Observações sobre a organização conceitual}

Após abordar a organização dos termos do campo conceitual resíduos nos diferentes tipos de texto nas duas línguas, passamos às questões sobre distribuição dos termos e às questões de equivalência.

É necessário lembrar, mais uma vez, que nosso trabalho de reconhecimento do vocabulário e das conceituações destinase a abastecer um glossário que toma o português como ponto de partida. A indicação de equivalências em alemão objetiva atender, entre outros usuários, também ao usuário tradutor. Ao longo de nosso reconhecimento, nos diferentes textos, é nele que pensamos em primeiro lugar.

Um problema bastante complexo, na nossa exploração, como se pôde perceber, é a questão das diferentes visões, em português e em alemão, sobre um mesmo conjunto conceitual. Essa diferença de classificação faz com que a equivalência denominativa, ao ser localizada, exija notas de uso para explicitar a 
relação existente entre um termo em português e seu equivalente em um dado tipo de texto. Além dessa necessidade, surgem ainda duas questões.

A primeira questão implica uma decisão sobre o que fazer, no glossário de Gestão Ambiental, com diferentes denominações existentes para um mesmo conceito. A solução que nos pareceu a melhor foi assinalar para o usuário que denominações são as empregadas com maior freqüência em diferentes documentos.

Nessa situação, para resíduos de serviços de saúde, por exemplo, foram encontradas, em português, as seguintes denominações: resíduos de serviços de saúde, resíduos sólidos de serviços de saúde, resíduos hospitalares, lixo de serviços de saúde e lixo hospitalar. Como equivalentes em alemão: Abfälle aus der Humanmedizin oder tierärztlichen Versorgung und Forschung, Klinikabfälle, Krankenhausabfälle, Krankenhausmüll e Klinikmüll.

Para evitar, porém, que um consulente tradutor ficasse sem saber qual dos termos usar, apresentamos, em nota de equivalência, uma escala de uso, ou seja, freqüências de uso dos diferentes termos averiguadas a partir da ferramenta de busca Google. Além disso, decidimos fornecer um esclarecimento sobre o âmbito em que os equivalentes em alemão são mais ou menos utilizados. Isso se pode perceber pelo protótipo de verbete abaixo indicado.

\section{residuos de serviços de saúde}

Fonte: Relatório Preliminar da Política Nacional de Resíduos Sólidos.

Definição: resíduos especiais provenientes de qualquer unidade que execute atividades de natureza médico-assistencial às populações humana ou animal, centros de pesquisa, desenvolvimento ou experimentação na área de farmacologia e saúde, bem como os medicamentos vencidos ou deteriorados.

OD: Resíduos Sólidos de Serviços de Saúde, Resíduos Hospitalares, Lixo de Serviços de Saúde, Lixo Hospitalar.

Sigla: RSS, RSSS.

Equivalentes: (1) Klinikabfälle m. Pl., (2) Krankenhausabfälle m. Pl., (3) Krankenhausmüll m. Sing., (4) Klinikmüll m. Sing., (5) Abfälle aus der Humanmedizin oder tierärztlichen Versorgung und Forschung m. Pl. 
Nota de uso dos equivalentes: Os termos (1), (2), (3) e (4) são utilizados em textos institucionais de divulgação publicados em websites; estão ordenados por freqüência de uso cf. dados do buscador www.google.de.

A longa expressão (5) ocorre apenas em textos legais alemães, especifica resíduos provenientes da medicina humana e da medicina veterinária, abrangendo resíduos de pesquisa veterinária. A ocorrência de (5) em outros tipos de texto é praticamente nula.

Uma segunda questão a resolver, no nosso glossário, a partir do reconhecimento conceitual e denominativo empreendido, é o das lacunas de designação entre os corpora em alemão e português. Afinal, conforme vimos, as tipologias de resíduos no Brasil e na Alemanha são bastante diferentes. Na perspectiva alemã, há um número grande de denominações para conceitos que, no Brasil, aparentemente não são dignos de menção.

Um exemplo bastante ilustrativo é o caso do termo alemão Sperrmüll (resíduos volumosos ou de difícil deslocamento). Essa expressão é muito utilizada e aparece tanto na legislação quanto em textos de websites. O termo Sperrmüll não encontra no Brasil, ainda, uma equivalência. Porém, por ser um termo muito utilizado e por aparecer sempre como subcategoria de Siedlungsabfälle (resíduos de povoamentos / urbanos), consideramos que mereceria haver uma informação sobre Sperrmüll no verbete resíduos urbanos.

Em seguida, como exemplo, vemos a nota do verbete resíduos urbanos. O esquema que a segue, embora não vá figurar no glossário, representa a situação conceitual expressa.

"O termo Siedlungsabfälle inclui uma categoria de resíduos denominada Sperrmüll, literalmente 'lixo que obstrui a circulação'. Sperrmüll corresponde a resíduos volumosos, como um móvel velho, refrigerador, bicicletas ou outros bens que precisam ser descartados. Esse tipo de resíduo ainda não tem denominação fixa equivalente no português brasileiro." 

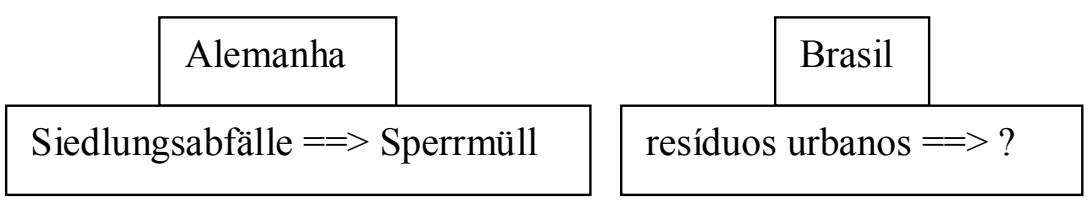

Outra diferença conceitual interessante é a existente para o termo resíduos. Em alemão, Abfälle corresponde somente a resíduos sólidos; se encontramos resíduos líquidos, deveríamos favorecer, em uma tradução, o termo Abwasser, e, se forem resíduos gasosos, Abluft ou Abgase, mas não há um hiperônimo na língua alemã como há na língua portuguesa. A ilustração a seguir representa essa situação:
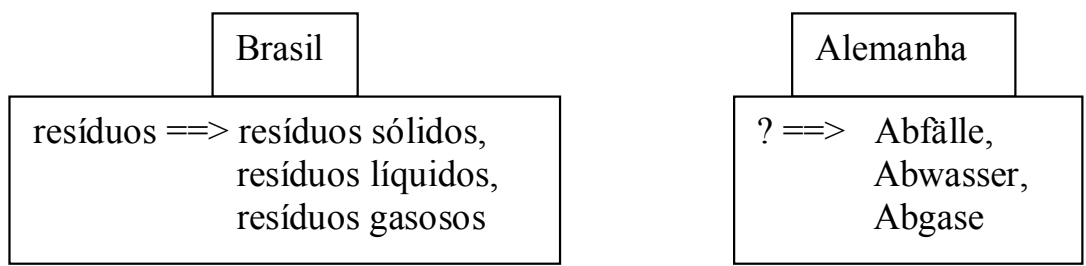

O símbolo ==> indica relação de hiperônimo - hipônimo

Por fim, é importante ressaltar que, para melhor informar um tradutor sobre o uso de cada termo equivalente em alemão, seria importante que fossem oferecidos contextos. Um exemplo de contexto para um equivalente em alemão para resíduos de serviços de saúde seria:

Diese Bestimmung schreibt vor, dass Abfälle vor der Deponierung zu sortieren und $z u$ behandeln sind. Weil Krankenhausabfälle nicht für das Sortieren und Verrotten in einer speziellen Anlage geeignet sind, müssen diese einer Verbrennung zugeführt werden.

http://www.uni-leipzig.de/ umwelt/archiv/abfallo4ukl.pdf, página verificada em 03/11/05

Todavia, em que pese à relevância desse tipo de informação, por questões editoriais, não temos certeza de que poderá figurar nos verbetes na versão impressa, sobretudo porque temos mais três línguas envolvidas no glossário: inglês, francês e espanhol. 


\subsection{Observação dos Komposita}

Concluída a observação-piloto sobre conceituações e denominações, passamos agora a relatar a nossa verificação sobre a incidência dos Komposita em contraste com as denominações em português. Essa parte do nosso trabalho foi feita apenas por amostragem, com a utilização de poucos itens de observação, embora tenha sido examinado todo o acervo textual já referido.

Como parâmetro para uma observação inicial, utilizamos as palavras de busca Abfall, Abfälle (incluindo a forma no dativo plural = Abfällen) e Müll. Averiguamos as distribuições de cada uma como determinante e/ou base de um Kompositum. Na comparação com o português, buscamos a presença, nos textos, de resíduo, resíduos e lixo.

Os Komposita examinados restringem-se aos formados no padrão substantivo + substantivo. Entendemos ser esse o padrão mais relevante para uma exploração inicial, sobretudo porque cerca de quatro quintos dos Komposita tendem a ter essa feição, conforme indicação da gramática Duden (1998). O foco sobre os Komposita também se justifica porque, segundo Welker (2001), o estilo nominal é característico da linguagem técnica e científica em alemão. E, como ressalta Pickbrenner (2006), mesmo que cada elemento do Kompositum pudesse, em tese, ser compreendido ao se examinar seus constituintes em isolado, só poderá ser bem compreendido tendo em vista seu contexto textual de ocorrência.

\subsubsection{Os Komposita}

Após a verificação dos corpora, averiguamos a presença muito rara de Komposita formados por mais de três elementos. Há quase três vezes mais Komposita de dois elementos do que com três. Vimos também que os elementos Abfall, Abfälle( $n)$ e Müll se posicionavam como "base", "primeiro determinante" ou "segundo determinante", não havendo nenhuma ocorrência como "terceiro determinante" ou além dessa posição.

Para melhor visualizar o posicionamento dos elementos em foco nos Komposita dos nossos corpora, vejamos o exemplo: 
Sondermüllverbrennungsanlage (Sonder+Müll+Verbrennung $+\mathbf{s}+$ Anlage)

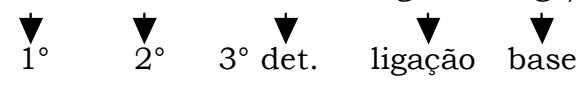

Dentre as três palavras de busca utilizadas (Abfall, Abfälle(n) e Müll), a mais encontrada, tanto nos textos mais especializados, quanto nos textos menos especializados, foi Abfall. Esse resultado foi, a princípio, contrário ao que verificamos em português.Nos textos brasileiros, o que se encontrou foi justamente a palavra resíduos como a predominante. Quer dizer, aparentemente, há uma diferença no uso de plural e singular do português para o alemão. Tal conclusão se mostrou falsa ao observarmos o posicionamento das palavras nos compostos.

Vimos que Abfälle(n) nunca ocorria como determinante nos Komposita, sendo usada como determinante sempre sua variante no singular (Abfall). Esse resultado corrobora a visão de Weinrich (1993), que diz: "Em todos os casos, a forma determinante no Kompositum aparece como lexema puro e não traz morfemas flexionais". Averiguamos também que as ocorrências de Abfall como base eram bastante limitadas, numa proporção média de uma ocorrência para cada cinco ocorrências de Abfälle(n). Para estabelecer um paralelo, no português, as ocorrências de resíduo em relação a resíduos se deram na proporção média de uma para vinte. Assim, mesmo sendo numa proporção menor que no português, percebemos que a ocorrência de bases (que geralmente correspondem à palavra inicial do português) era predominante no plural, assim como há uma predominância do plural no português.

É importante ressaltar as ocorrências do elemento como base, já que é a base que marca o hiperônimo, como, por exemplo: residuos hospitalares cujo equivalente em alemão é Krankenhausabfälle.

Nas ocorrências da palavra Müll, a divisão entre textos mais e menos especializados se mostrou relevante. A utilização geral de Müll foi, em relação a Abfall e Abfälle(n) somados, em média, de uma para cada seis. Porém, ao observarmos os corpora separadamente, observamos que nos textos mais especializados a ocorrência relativa foi de uma para trinta, enquanto no texto menos especializado a ocorrência relativa foi de uma para três.

TRadTerm, 12, 2006, p. 269-292 
De outro lado, a proporção nos textos em português da palavra lixo em relação a resíduo e a resíduos somados, foi, em média, de uma para dez, sendo que também houve a mesma situação em relação à especialização dos textos. As ocorrências de Müll deram-se ainda, em sua maioria, como determinante, numa relação média de duas ocorrências como determinante para cada uma ocorrência como base.

\section{Conclusões}

A partir dos resultados apresentados sobre o reconhecimento terminológico e conceitual, evidencia-se a dificuldade de se colocar em paralelo duas terminologias geradas em línguas distintas. A distinção denominativa pode ser percebida, entre várias situações, pelas diferentes maneiras de classificar resíduos sólidos. No Brasil, vemos que esses resíduos tendem a ser classificados por sua composição; na Alemanha, a classificação é feita segundo os diferentes tipos de destinação que um resíduo possa ter.

No decorrer da pesquisa, pareceu-nos especialmente complexo depreender a organização da classificação brasileira para resíduos. Verificamos inconsistências nos textos normativos e paralegais, as quais parecem repercutir sobre nossos textos de divulgação.

De outro lado, percebemos, por exemplo, que os textos legais alemães, embora detalhados em sua classificação, utilizam uma terminologia que emprega designações bastante extensas, cuja interpretação pode ser mais complexa em função da longa sucessão de determinantes unidos a uma base. De modo inverso, em websites, há Komposita de feição mais simples, o que pode indicar um interesse de facilitação da informação.

Já no que diz respeito aos Komposita, percebemos que há uma tendência maior à formação de Komposita de dois elementos em detrimento de Komposita maiores, corroborando as averiguações dos trabalhos exploratórios de Zilio et al. (2004) e os resultados da pesquisa de Leipnitz (2005). Vimos também que as ocorrências de Abfalle Abfälle(n) são predominantes em rela- 
ção a Müll, assim como resíduo e resíduos em relação a lixo. A tendência na denominação de categorias de resíduos é para o uso do plural, como, p. ex., Krankenhausabfälle (resíduos hospitalares).

Outro fator a destacar é que a divisão metodológica entre textos mais e menos especializados se mostrou válida para delimitar mais precisamente os usos das terminologias em diferentes cenários comunicativos e ambientes textuais. Uma evidência disso é que os termos lixo e Müll aparecem de forma muito mais freqüente em textos de websites, sendo raros em textos normativos.

Para finalizar, cabe registrar que as dificuldades experimentadas ao longo do nosso reconhecimento das terminologias de Gestão Ambiental, sobretudo na parte do reconhecimento conceitual e denominativo a partir dos textos nas duas linguas, foram, na verdade, nossas grandes motivadoras. Afinal, essa foi uma exploração, um verdadeiro "reconhecimento de terreno", que visou embasar todo um trabalho em larga escala na parte da localização de equivalências em alemão para os termos em português. Além disso, permitiu-nos reconhecer toda uma gama de informações que seria preciso agregar aos verbetes de modo a atender bem ao nosso usuário, especialmente ao tradutor, um profissional que, infelizmente, tende a ser pouco lembrado pelas equipes que produzem obras dicionarísticas.

\section{Referências bibliográficas}

\section{Bibliografia teórica}

BERBER SARDINHA, Tony. (2004) Lingüistica de Corpus. Barueri: Manole.

CORT, Josef de. (1982) Nominale Komposita aus drei oder mehr Konstituenten: Bemerkungen zu der Komposition in der wissenschaftlichen Fachsprache der Wirtschaft. In: Fachsprache $n^{\circ}$ 9, Heft 1.

DUDEN, Grammatik der deutschen Gegenwartssprache. (1998) 6 $6^{a}$ ed. revisada. Mannheim, Leipzig, Wien, Zürich: Dudenverlag.

HOFFMANN, Lothar. (2004) Conceitos básicos da lingüistica de linguagens especializadas. In: KRIEGER, Maria da Graça \& ARAÚJO, 
Luzia. Cadernos de Tradução, $\mathrm{n}^{\circ} 17$, A terminologia em foco, outubro/dezembro de 2004. Porto Alegre: UFRGS, p. 80. Tradução de Ulla Pedde Muss e Maria José Bocorny Finatto.

KRIEGER, Maria da Graça; MACIEL, Anna Maria Becker; ROCHA, João Carlos de Carvalho; FINATTO, Maria José Bocorny \& BEVILACQUA, Cleci Regina. (1998) Dicionário de Direito Ambiental: terminologia das leis do meio ambiente. Porto Alegre, Brasília: Ed. Universidade/ UFRGS/Procuradoria Geral da República.

; FINATTO, Maria José Bocorny \& REUILLARD, Patrícia Chittoni Ramos. (2004) Glossário multilingüe de direito ambiental internacional: terminologia dos tratados. Rio de Janeiro: Forense.

KRIEGER, Maria da Graça \& FINATTO, Maria José Bocorny. (2004) Introdução à Terminologia. Teoria \& Prática. São Paulo: Contexto, p. 134.

LEIPNITZ, Luciane. (2005) Compostos Nominais do Alemão na Linguagem Médica em Tradução. Dissertação (Mestrado em Teorias do Texto e do Discurso) - Universidade Federal do Rio Grande do Sul. Orientador: Maria José Bocorny Finatto.

PICKBRENNER, Minka B. (2006) Termos compostos em língua alemã: uma contribuição para o ensino de leitura instrumental em direito. Dissertação (Mestrado em Teorias do Texto e do Discurso) - Universidade Federal do Rio Grande do Sul. Orientador: Maria José Bocorny Finatto.

WAHRIG, Gehard. (2000) Deutsches Wörterbuch. Gütersloh/München, Bertelsmann Lexikon Verlag

WEINRICH, Harald. (1993) Textgrammatik der deutschen Sprache. Mannheim, Leipzig, Wien, Zürich: Dudenverlag.

WELKER, Herbert Andreas. (2001) Gramática Alemã. $3^{a}$ ed. Brasília: Editora da Universidade Federal de Brasília.

ZILIO, Leonardo; FICHTNER, Mônica Linck Feijó \& FINATTO, Maria José Bocorny. (2004) Estudo de termos compostos na língua alemã: perfis de Komposita no Protocolo de Quioto e suas correspondências em um glossário multilíngüe de gestão ambiental. In: ROCHA, Marininha Aranha (org.). Livro de Resumos. XVI Salão de Iniciação Científica e XIII Feira de Iniciação Científica da UFRGS. Porto Alegre: UFRGS, p. 890-891. Versão em CD-ROM. ; FINATTO, Maria José Bocorny. (2005) Resíduos e Abfälle: A busca e o tratamento da equivalência terminológica. In: ROCHA, Marininha Aranha (org.). Livro de Resumos. XVII Salão de Iniciação 
Científica e XIV Feira de Iniciação Científica da UFRGS. Porto Alegre: UFRGS, p. 959. Versão em CD-ROM.

\section{Bibliografia dos corpora}

$1^{\circ}$ GUIA DE TECNOLOGIAS AMBIENTAIS BRASIL-ALEMANHA 19992000 / 1. Deutsch-Brasilianischer Führer für Umwelttechnologien 1999-2000. (2000) São Paulo: Câmara de Comércio e Indústria Brasil-Alemanha de São Paulo.

AMBIENTEBRASIL: Portal ambiental. Disponivel em: $<$ www.ambientebrasil.com.br>.

BAYERISCHES Staatsministerium für Umwelt, Gesundheit und Verbraucherschutz. Disponível em: <www.stmugv.bayern.de>.

KAPAZ, Emerson. (2001) Relatório Preliminar da Política Nacional de Resíduos Sólidos. Projeto de Lei 203/91 Câmara Federal

RESOLUÇÃO CONAMA No 005, de 5 de agosto de 1993. (1993) Disponivel em: <http://www.lei.adv.br/005-93.htm>.

UMWELTDATENBANK. Disponivel em: <www.umweltdatenbank.de>. VERORDNUNG zur Umsetzung des Europäischen Abfallverzeichnisses vom 10. Dezember 2001 zuletzt geändert durch Verordnung vom 24. Juli 2002. (2002) Bonn: Bundesgesetzblatt Jahrgang 2001 Teil I Nr.65.

WEB-RESOL: Resíduos Sólidos: Instituto para a Democratização de Informações sobre Saneamento Básico e Meio Ambiente. Disponível em: <www.resol.com.br>.

TradTerm, 12, 2006, p. 269-292 